\title{
Pragmatic Functions of Questioning in TV Interview Program
}

\author{
Weihong Chen \\ College of Foreign Languages, Quanzhou Normal University, \\ Quanzhou 362000, Fujian, P. R. China \\ chwh518518@163.com
}

Key Words: Special speech act, Questioning pragmatic functions

\begin{abstract}
As a special speech act and language use, questioning acts as a pragmatic strategy in TV interview programs. From the perspective of adaptive pragmatics, the paper intends to reveal that the host's dynamic questioning in TV interview programs can realize various pragmatic functions in specific contexts as well as accomplish certain communicative needs.
\end{abstract}

\section{Introduction}

TV interviews are task-driven, whose main function is to request for information in Q-A format. But this doesn't mean that it does not embrace other pragmatic functions. As a special speech act, the dynamic questioning in TV interview programs can fulfill various pragmatic functions in specific contexts as well as accomplish certain communicative needs.

According to Mey (2001:10), "linguistic functions of use are best studied in situations where people interact normally, using language in situations where people interact normally, using language face to face” [1].Therefore, to explore functions accomplished by the questioning, the author carry out the present study based on analyzing naturally occurring data collected from some famous interview programs in China. It turns out that functions of questioning in TV interview programs mainly includes: 1) controlling topics and turns; 2) seeking and checking information; 3) accomplishing some non-questioning actions, such as position taking, sympathy arousing, challenging, etc. The number and the percentage of each function are shown at Table 1.

Table 1 Frequency of Pragmatic Functions of Questioning in TV Interview Programs

\begin{tabular}{|c|c|c|c|c|c|}
\hline Functions & $\begin{array}{l}\text { Interview } \\
\text { Programs }\end{array}$ & Frequency & Percentage & Frequency & $\begin{array}{l}\text { Percentag } \\
\mathrm{e}\end{array}$ \\
\hline \multirow{3}{*}{$\begin{array}{l}\text { Topic and } \\
\text { Turn } \\
\text { Management }\end{array}$} & Duihua & 185 & $95.8 \%$ & \multirow{3}{*}{730} & \multirow{3}{*}{$97.7 \%$} \\
\hline & $\begin{array}{l}\text { Yang Lan One } \\
\text { on One }\end{array}$ & 98 & $98 \%$ & & \\
\hline & Lu Yu You Yue & 447 & $98.4 \%$ & & \\
\hline \multirow{3}{*}{$\begin{array}{l}\text { Information } \\
\text { Seeking and } \\
\text { Checking }\end{array}$} & Duihua & 80 & $41.4 \%$ & \multirow{3}{*}{419} & \multirow{3}{*}{$56.1 \%$} \\
\hline & $\begin{array}{l}\text { Yang Lan One } \\
\text { on One }\end{array}$ & 52 & $52 \%$ & & \\
\hline & Lu Yu You Yue & 287 & $63.2 \%$ & & \\
\hline \multirow{3}{*}{$\begin{array}{l}\text { Position } \\
\text { Taking }\end{array}$} & Duihua & 43 & $22.3 \%$ & \multirow{3}{*}{80} & \multirow{3}{*}{$10.7 \%$} \\
\hline & $\begin{array}{l}\text { Yang Lan One } \\
\text { on One }\end{array}$ & 12 & $12 \%$ & & \\
\hline & Lu Yu You Yue & 25 & $13.5 \%$ & & \\
\hline \multirow{3}{*}{$\begin{array}{l}\text { Sympathy } \\
\text { Arousing }\end{array}$} & Duihua & 5 & $2 \%$ & \multirow{3}{*}{24} & \multirow{3}{*}{$3.2 \%$} \\
\hline & $\begin{array}{l}\text { Yang Lan One } \\
\text { on One }\end{array}$ & 1 & $1 \%$ & & \\
\hline & Lu Yu You Yue & 18 & $3.9 \%$ & & \\
\hline Total & & & & 747 & $100 \%$ \\
\hline
\end{tabular}




\section{Pragmatic Functions Accomplished by Questioning in TV Interview Programs}

After the scrutiny of the data collected, the author made the above table, which directly shows the frequency of each function realized in the host's questioning in TV interview programs. It should be pointed out that in the same stretch of talk, functions of the host's questioning may overlap, which may contain more than one function. Therefore, primary functions of the host's questioning will all be identified. The functioning process of the host's questioning will then be explained in the following part.

\section{Topic and Turn Management}

Topic and turn management contains three aspects: topic initiating, maintaining and shifting. Since the interview is usually task-oriented, the host will make full preparation for the whole process as to how to begin, extend and end the conversation, most of which is realized by questioning. The host's questioning acts as topic management indicates the institutional power the host is endowed with, which plays an important part on pushing the conversation to move on. Look at Example 1.

\section{Example 1}

Host: Hello, Mr. Duan. Welcome to our studio. Just now we have seen the video of the magnificent building built more than 1000years ago and enormous changes happening in the land. As a native, do you feel shocked?

Interviewee: I'm extremely shocked, for I have been living here since a child and admiring Daming Palace. And now I'm appointed to build Daming Palace National Ruins Park.

Host: Can the land really re-create its ever magnificent history?

Interviewee: It should be. Tours back home and abroad will be shocked by our Daming Palace National Ruins Park.

At the beginning of the interview, a short film concerning the history of Xi'an was played on the big screen in the studio as background introduction to the interview. After it ended, the host began to utter his questioning as to start the conversation with the interviewees. In his first questioning, he asked about the guest's reaction about the short introduction. Such way of questioning is very common at the beginning of an interview. And then, on hearing the guest's answer, the host presented the main topic of the interview-Xi'an's reconstruction of historical sites via questioning, announcing the formal beginning of the whole program. Here, it is greatly obvious that questioning can function as devices of topic initiating, maintaining as well as shifting. Its role of topic managing in TV interview programs is self-evident.

\section{Example 2}

Host: But, Mr. Jiang Jingguo didn't leave any legacy, right?

Interviewee: He left nothing.

In the second part of the adjacent pair prior to Example 2, the guest made a long and detailed narration of his family history and people's misunderstanding on his coming to the mainland to mourn his ancestors. When he talked of people's rumor that he intended to fight for his father's legacy, the host cut him short with her questioning to mention her obtained indirect information that Mr. Jiang Jingguo didn't leave any legacy. And then the guest began to state that his father didn't leave something valuable. Therefore, the host's questioning here serves as a subtopic and an addition to the main topic in the stretch of talk. Instead of simply answering "yes" or "no" to the host's questioning, the guest makes further statement and explanation, indicateing that he treats the host's questioning as a fact instead of interrogation checking for the information. Obviously, the host's questioning here is not used to make a claim, nor is it used to pursue confirmation, for it just leads to the guest's further description added to the main topic on the relationship between his father and him. Therefore, it indeed acts as subtopic initiation, which is seen as one of the essential components constituting the whole interview story. Here, when the host embarks upon her institutional power, the 
guest displays positive cooperation with her by continuing to give more details to the host's questioning, which is beneficial to the accomplishment of this new subtopic.

\section{Information Seeking and Checking}

In interview programs, questions are set to ask for information, just in line with Churchill (1978)'s claim that all questions are technically requests for information in interview [2]. Look at Example 3.

\section{Example 3}

Host: The Low-Carbon Lifestyle you propose demonstrates a kind of balance between economic development and environmental protection you just mentioned. Then, can you tell everyone, what kinds of behavior can be exactly defined as low-carbon lifestyle in your current life after all? Interviewee: This is simple, but I was not sure several years ago.

Seeking information is the main function among the host's all pieces of questioning in TV interviews. In Example 3, the host is probing information concerning low carbon way of living and economy. The host's questioning here acts as requesting for information about low carbon ways of living in the guest's everyday life, so as to obtain further information about the guest's attitudes and actions on choosing a low carbon way of living. Thus, the host can focus on the main topic of the interview as well as extend the conversation for more details.

\section{Example 4}

Host: There is a guy named Pang Hong in "My Long March". I heard you wanted to dismiss him when the march covered only 5 miles, right?

Interviewee: Yes. Indeed, I once extremely hated him..

The host's questioning is obviously designed to check the information she has obtained indirectly, to pursue confirmation or verification from the guest. As is said previously, as the presenter of an interview, the host is obliged to be alert on information seeking and checking as possible as he/she could. In the above example, the host mentions an unhappy event occurring during the new long march initiated by the guest. Since the information was gained indirectly, the host raises the question, expecting the guest to verify it. Information checking includes many respects, such as, checking related information acquired indirectly as the above example shows, verifying information the guest just mentioned in previous answers, confirming the host's suppose from the guest's last answer, etc.

\section{Position Taking}

Neutralism is one of the remarkable features of interview programs, which requests that the hosts should be, like other journalists, objective and unbiased in their communication with the guest. Clayman (1998) studies the practices of TV news interviews in which neutrality is claimed to be the backdrop for discussion[3]. To show their neutral stance in interview programs, the host will usually articulate questioning in the communication instead of declarative, imperative and other sentence pattern, for apparently the former sounds less sure, controversial and offending than the latter. Sometimes, they will utter their questioning with the third party tone by beginning their questioning with "people say/think/believe/suppose..." to show their neutrality in the interview. However, many of their questions do indicate their agreement, disagreement or rejection of the guests' stated opinions or behaviors. That is, questioning can be used by the host to display his real thought or opinion. It does not ask for information from the guest but conveys it to him/her instead. For example, their questioning will fulfill their purposes in an indirect and soft way. Look at the following example.

\section{Example 5}

Host: What do you mean by saying that the complicated generation will be gone? Only you are complicated?

Interviewee: Yes, most complicated and cynic people like me have died. 
The underlined question can be interpreted as the interviewer's disagreement and refuting because of the guest's opinion expressed in the previous turn. The guest supposes that the complicated people of his generation will be gone in one day. Obviously, the host doesn't think so, who conveys her disagreement and refutes his opinions by means of the two underlined pieces of questioning in the above example. The second part of the adjacency pair is a standard answer to the form of yes/no questions. The guest says "yes" and then makes an explanation to why he thinks they will be the past. Therefore, the host's questioning acts as indicating the host's stance and position.

\section{Example6}

Host: I assume that directors are all full of passion. Well, I'm wrong... (Question 1)

Interviewee: I think I'm a person of passion, do you think so?

Host: Er, can we define you as a person of passion? (Question 2)

Interviewee: Well, I admit that I'm a man without too much unstable emotions.

Question 1 in the above example shows the host's negative reflection to the guest's answer in his answer prior to this question. In his previous answer, the guest says that he is passionate in the studio, just as he was in his shooting scene. At hearing what he said, the host expresses her resistance at once by questioning. The premise in the guest's utterance is that he believes himself passionate in directing the film, which is in conflict with the host's definition on passion. The host immediately shows her disagreement by questioning. However, the guest doesn't answer the question. Instead, he uses a rhetorical question to express that he is passionate, which is again denied by the host by another question. The host's disagreement is reinforced and strengthened by her second questioning right after the guest's reaction. The second part of the adjacency pair here is obviously by no means a standard answer of "yes" or "no" to the yes/no question form, but is replaced by the guest's explanation which shows his different understanding on passion from others. Therefore, in the above examples, the two questioning utterances emphasize the host's disagreement and argument against the guest's claim.

\section{Sympathy Arousing}

Questioning as sympathy arousing often appears in discussing environmental protection or other serious issues. This kind of questioning is devoted to seeking a common psychological ground shared by the participants. To be specific, it will be used to evoke audiences' sympathy and compassion, attracting their attention, concern, involvement or pursuing their approval and agreement.

\section{Example 7}

Host: Indeed, I think that teachers in Beichuan Middle School are under great pressure, which is not only caused by their job. You are also under emotional pressure continually, right?

Interviewee: Yes. It is true. But just as I said once before, the earthquake could not quake our willingness, strength and spirits no matter how mighty it seems. We will be on our feet once again.

As is mentioned above, questioning as sympathy arousing usually comes out in talking about serious topics such as disasters like earthquake, mine tragedy, landslide, etc. Therefore, here the host used a lot of pre-sequences before uttering his questioning, thus making his questioning sound more persuasive, appealing and touching. Especially, the host often outpours his/her sincere sympathy for the difficulties the guests have ever encountered, which will greatly shock the audience and arouse their great concern and compassion.

\section{Conclusion}

After a scrutinized study of data collected from China's famous TV interview programs, the paper makes efforts to display various pragmatic functions and corresponding communicative expectation fulfilled and accomplished by dynamic questioning in TV interview programs. It turns out that the 
host's questioning can serve as an indispensible pragmatic strategy and thus helps develop his/her harmous and friendly communication with interviewees.

\section{Acknowledgements}

This work was financially supported by Social Science Research Pragramme of the Education Department of Fujian Province(JAS1423).

\section{References}

[1] Mey, J.L.: Pragmatics: An Introduction (Blackwell, England 2001).

[2] Churchill: Questioning Strategies in Sociolinguistics (Newbury House, USA1978).

[3] Clayman, Steven: submitted to Journal for the Study of Discourse (1993). 